\title{
Time and Temporality in a Selection of Narratives By Kurt Vonnegut and Brian Evenson
}

\author{
Sana Daaloul \\ Facultés des lettres, des arts ET des humanités Université la Manouba, Tunisia
}

\begin{abstract}
This paper explores the relation between time and literature which is disseminated across literary texts. The analysis aims at giving the contextual points of departure from which to understand the fundamental turn taken in the literary path which provokes a new kind of thinking related to and dependent on other fields such as philosophy and science. At the cross roads of American Literature, one can easily determine that Kurt Vonnegut and Brian Evenson establish a broader perception of time and temporality in their narratives as they thoughtfully probe into the most profound aspects of ontological and scientific matters related to time perceptions and conceptions. I intend, through the analysis of time and temporality within their fictional as well as non-fictional texts, to cast light on the changes in thinking time and temporality, and to map out the philosophical approaches with which they engaged their writings. The main concern of this paper is based on Deleuze's constructive view that represents the three powers of thinking that are science, art and philosophy. The model of the three powers of thinking is applied in this analysis. The paper brings to the fore Deleuze and Guattari's speculation, American Science Fiction literature in general, and Vonnegut and Evenson's fiction in specific. A final aspect which this paper deals with is that in terms of Deleuzian's "plane of immanence" the analysis of literary narratives represents the plane upon which philosophical concepts are built to be open to all possible creations and engender different types of becoming.
\end{abstract}

Keywords: American literature; philosophy; Science Fiction; 